\title{
Vimentin contributes to human mammary epithelial cell migration
}

\author{
Christine Gilles ${ }^{1, \star}$, Myriam Polette ${ }^{2, \star, \neq}$, Jean-Marie Zahm² ${ }^{2}$ Jean-Marie Tournier ${ }^{2}$, Laure Volders ${ }^{1}$, \\ Jean-Michel Foidart ${ }^{1}$ and Philippe Birembaut ${ }^{2}$ \\ ${ }^{1}$ Laboratory of Tumor and Developmental Biology, University of Liège, CHU Sart-Tilman, B23, 4000 Liège, Belgium \\ 2Unité INSERM U.514, Laboratoire Pol Bouin, IFR 53, CHU Maison Blanche, 45, rue Cognacq-Jay, 51100 Reims, France \\ *The first two authors contributed equally to this paper \\ ‡Author for correspondence (e-mail: myriam.polette@univ-reims.fr)
}

Accepted 8 October; published on WWW 30 November 1999

\section{SUMMARY}

Vimentin expression in human mammary epithelial MCF10A cells was examined as a function of their migratory status using an in vitro wound-healing model. Analysis of the trajectories of the cells and their migratory speeds by time lapse-video microscopy revealed that vimentin mRNA and protein expression were exclusively induced in cells at the wound's edge which were actively migrating towards the center of the lesion. Actin labeling showed the reorganization of actin filaments in cells at the wound's edge which confirmed the migratory phenotype of this cell subpopulation. Moreover, the vimentin protein disappeared when the cells became stationary after wound closure. Using cells transfected with the vimentin promoter controlling the green fluorescent protein gene, we also demonstrated the specific activation of the vimentin promoter in the migratory cells at the wound's edge. Transfection of the antisense vimentin cDNA into MCF10A cells clearly reduced both their ability to express vimentin and their migratory speed. Taken together, these observations demonstrate that vimentin is transiently associated with, and could be functionally involved in, the migratory status of human epithelial cells.

Key words: Vimentin, Migration, MCF10A, EMT, Epithelial-tomesenchymal transition, Epithelial cell

\section{INTRODUCTION}

Vimentin is a type III intermediate filament protein normally expressed in cells of mesenchymal origin (Steinert and Roop, 1988). However, vimentin expression has been described in epithelial cells involved in pathological or physiological processes which require epithelial cell migration. Accordingly, accumulating data now support the concept that epithelial cell acquisition of migratory and/or invasive properties is associated with the loss of epithelial characteristics and the gain of mesenchymal properties, a phenomenon referred to as epithelial-to-mesenchymal transition (EMT). Several other groups of molecules (including cell-cell adhesion molecules, cell-substrate adhesion molecules, proteases, transcription factors...) have been implicated in the EMT associated with different physiological or pathological processes (Savagner et al., 1994; Guarino, 1995; Hay, 1995; Gilles and Thompson, 1996). More specifically, vimentin has been described in epithelial cells involved in embryological and organogenesis processes (Guarino, 1995; Hay, 1995), wound healing (SundarRaj et al., 1992), placentation (Nawrocki et al., 1997) or tumor invasion (Ramaekers et al., 1983; Savagner et al., 1994; Guarino, 1995; Gilles and Thompson, 1996; Gilles et al., 1996). Similarly, vimentin expression has been detected in several human epithelial tumor cell lines. Comparative studies have nevertheless shown that vimentin expression is restricted to those cell lines displaying high invasive abilities, suggesting that vimentin is related to high invasive abilities rather than being non-specifically induced by culture conditions (Sommers et al., 1989, 1992; Gilles et al., 1994a,b; Gilles and Thompson, 1996; Hendrix et al., 1996; Polette et al., 1998). Furthermore, vimentin antisense transfection into invasive, vimentin-positive breast carcinoma MDA-MB-231 cells decreased their in vitro invasive properties, thereby suggesting that vimentin plays a functional role in invasion (Hendrix et al., 1997). However, because it is difficult to identify a migratory cell in vivo and because vimentin expression is stable in most human cell lines, it is still unclear whether or not vimentin expression is associated with the migratory status.

Indeed, the sequence of events implicated in the EMT and its regulation (induction or repression) are still poorly understood. This lack of information partly results from the absence of adequate in vitro human models allowing the study of EMT dynamics. Indeed, EMT has been primarily induced by various means and studied in two cellular models: MardinDarby canine kidney (MDCK) cells (Weidner et al., 1990; Behrens et al., 1993) and rat bladder carcinoma NBTII cells (Boyer et al., 1989; Vallés et al., 1990; Savagner et al., 1994). Vimentin expression was for instance induced in NBTII cells in response to growth factors (such as acidic fibroblast growth factor or hepatocyte growth factor) or several collagen types (Boyer et al., 1989; Zuk et al., 1989; Tucker et al., 1990; Vallés et al., 1990; Savagner et al., 1994). Transfection of MDCK cells with the SV40 large T antigen has also been shown to 
generate a stable EMT-derived phenotype with enhanced vimentin expression (Martel et al., 1997). Using a mouse mammary epithelial cell model, Lochter et al. (1997) have also demonstrated that the transfection of the matrix metalloproteinase stromelysin-1 induces an EMT, including vimentin upregulation, associated with an invasive behaviour. Data concerning the dynamics and regulation of cell migration/invasion as a function of vimentin expression in human cells are however scarce since most human cell lines display relatively stable phenotypes and cannot be easily induced to express invasive/EMT-derived properties. Most data on human epithelial cell migration have therefore been obtained on primary cells, which retain more plasticity than most human cell lines and can be induced to migrate under conditions mimicking wound-healing or organogenesis. Thus, vimentin expression has been described in human keratinocytes involved in the outgrowth of keratinocyte sheets or in the leading edge of a wounded monolayer (Biddle and Spandau, 1996). Similarly, we reported vimentin expression in normal human bronchial cells studied in an in vitro woundhealing model (Buisson et al., 1996). However, until now, a human model enabling vimentin expression to be studied as a function of the migratory status was lacking. Thus, vimentin association with and functional contribution to cell migration remain to be elucidated.

In the present study, we used the human breast cell line MCF10A in an in vitro wound-healing system to establish a human model of EMT to study the dynamics of vimentin expression as a function of the migratory status. We used timelapse video microscopy to quantify cell migration and herein report the transient association between vimentin expression and cell migration. We also used antisense transfection strategies which demonstrated a functional contribution of vimentin to epithelial cell acquisition of migratory properties.

\section{MATERIALS AND METHODS}

\section{Cell culture}

Human mammary epithelial MCF10A cells were obtained from the American Type Culture Collection (Rockville, MD). Their growth medium was composed of HAM F12 and Dulbecco modified Eagle's medium (DMEM) 1:3 (v/v) supplemented with $20 \mu \mathrm{g} / \mathrm{ml}$ of adenine, $5 \mu \mathrm{g} / \mathrm{ml}$ of insulin, $0.5 \mu \mathrm{g} / \mathrm{ml}$ of hydrocortisone, $2 \mathrm{ng} / \mathrm{ml}$ of EGF, 5 $\mu \mathrm{g} / \mathrm{ml}$ of transferrin, $1.5 \mathrm{ng} / \mathrm{ml}$ of triiodothyronine and $10 \% \mathrm{FCS}$. The different MCF10A transfectants generated in this study were cultivated in the same medium. MDA-MB-231 human breast mammary carcinoma cells were also obtained from the American Type Culture Collection and were maintained in DMEM supplemented with 10\% FCS. Primary human airway cells were prepared as previously described (Zahm et al., 1997; Legrand et al., 1999). Cultures were maintained at $37^{\circ} \mathrm{C}$ and were Mycoplasma-free, as assessed with the Genprobe kit (Genprobe, San Diego, CA). All chemicals and culture media were purchased from Sigma Chemical Co. (St Louis, MO), Life Technologies (Gaithersburg, MD) or Boehringer (Boehringer Mannheim, Mannheim, Germany).

\section{Vector constructs}

The vimentin promoter-EGFP-1 vector (VP-EGFP) was constructed by cloning an EcoRI-BamHI 1.5-kb fragment of the human vimentin 5 '-upstream region into the multiple cloning site of the promoter-less EGFP-1 vector (Clonetech, Palo Alto, CA), containing a red-shifted variant of the green fluorescent protein (GFP) encoding gene as the reporter gene. This fragment, described and cloned as the vimentin promoter (Rittling and Baserga, 1987), was isolated from pG4F1EM1.5, kindly provided by Dr Rittling (Temple University Medical School, Philadelphia, PA). The pEGFP-1 vector was used as the control vector.

The vimentin sense and antisense expression vectors (pIRES-VimS and pIRES-VimAS, respectively) were constructed by cloning the sense or antisense orientated 1.8 -kb human vimentin cDNA into the EcoRI site of the pIRESpuro vector (Clonetech). The human vimentin cDNA (Sommers et al., 1989, 1992) was obtained from the EcoRI digestion of pCMV-VIM kindly provided by Dr Gelmann (Lombardi Cancer Center, Georgetown University, Washington, DC). The pIRES-EGFP vector, containing the EGFP reporter gene cloned into pIRESpuro was used as a control vector. The pIRES vector contains the internal ribosome entry site from the encephalomyocarditis virus which allows the translation of two open reading frames from a single mRNA. The mRNA generated from the pIRES-VimS and pIRESVimAS constructs are therefore bicistronic and easily distinguishable by northern blotting from the endogenous vimentin mRNA because of their bigger size.

\section{Transfection}

Stable transfection of MCF10A cells were performed with the different vector constructs in serum-free medium at $200 \mathrm{~V}$ and 960 $\mu \mathrm{F}$ using a gene pulser system (Bio-Rad, Richmond, CA). The transfected populations were then subjected to a selective pressure with geneticin G418 (for the EGFP-1 constructs) or puromycin (for the pIRESpuro constructs). For each transfection, several clones and several pooled transfected populations were isolated and characterized.

\section{Growth curves}

$5 \times 10^{4}$ cells per well (in triplicates) were plated into 24 -well plates in growth medium then sonicated in PBS at different time intervals (3, 24, 48, 72, 96 hours and 7 days). Fluorimetric DNA titration was performed on sonicated cells and used as an indicator of cell density. The doubling time was estimated on the linear part of the curves.

\section{In vitro wound induction procedure and the ring system}

Glass coverslips (22 $\mathrm{mm}$ in diameter) were incubated for 3 hours with a solution containing $250 \mu \mathrm{g} / \mathrm{ml}$ of cyanamide (Sigma) and 250 $\mu \mathrm{g} / \mathrm{ml}$ of collagen type I extracted from rat tails. The collagencoated coverslips were then allowed to dry under a Laminar-flow hood. Twenty-four hours before wound induction, $5 \times 10^{5}$ cells were seeded in growth medium on these collagen-coated glass coverslips. An in vitro wound was then created in the middle of the monolayer with a $1 \mu \mathrm{l}$ drop of $1 \mathrm{M} \mathrm{NaOH}$ which was immediately and extensively washed out with PBS (as described by Zahm et al., 1997; Legrand et al., 1999). Cells were then covered with the appropriate medium: growth medium for regular experiments or FCS+EGF-free growth medium for EGF induction experiments. For these latter, human recombinant EGF (Boehringer) was added to the medium at a final concentration of $20 \mathrm{ng} / \mathrm{ml}$. These cultures were then processed for the quantifications of wound closure, and cell migration speeds and cell trajectories, and immunolabeling or in situ hybridization.

An alternative migration-induction procedure was also used, which we will refer to as the ring system; it consists in plating $5 \times 10^{4}$ cells inside a 6-mm glass ring placed in the middle of a collagen-coated coverslip. Twenty-four hours after plating, the glass ring was removed and the cells were covered with growth medium. In this model, the cells migrate as an outgrowth from the confluent area initially delimited by the ring. As described below, the migratory speeds and trajectories of the cell nuclei can be quantified and analyzed. This ring system was used to study sense and antisense transfectants because this procedure is easier to handle when a large number of cell lines are to be examined. 


\section{Quantification of the wound closure}

Every 24 hours after wound induction, the monolayers were placed on the stage of an inverted microscope (Nikon TMS-F, Tokyo, Japan), connected to a video CCD camera (Cohu 4700, San Diego, CA) and a video monitor (PVM 1371, Sony, Japan), so as to visualize the wound's edge and measure the wound's area.

\section{Quantification of cell migration speeds and trajectories}

Wounded monolayers were incubated with a fluorescent nuclear dye (Hoechst 33258, Molecular Probes, Eugene, OR). They were then placed in the environmental chamber $\left(37^{\circ} \mathrm{C}, 5 \% \mathrm{CO}_{2}\right)$ of a Zeiss IM35 inverted microscope (Zeiss, Oberkochen, Germany) equipped with an epifluorescence illumination source (excitation filter at $360 \mathrm{~nm}$; emission filter at $510 \mathrm{~nm}$ ) and a low level SIT camera (Lhesa 4036) controlled by a microcomputer (SparcClassic Workstation). An image was collected every 10 or 15 minutes during 1 hour. Cell migration was characterized and quantified using a previously described software program (Zahm et al., 1997) that measures the nuclei trajectories within the hour of observation as well as the cell migration speed.

\section{Immunofluorescence}

Monolayers were fixed with cold methanol (or 4\% paraformaldehyde in PBS if GFP-vimentin covisualization was needed) for 10 minutes, saturated for 30 minutes with $3 \%$ BSA in PBS and then processed for single vimentin or double vimentin-actin immunolabeling.

For vimentin labeling, monolayers were successively (after intermediate washes) incubated for 1 hour with a monoclonal antibody to vimentin (Dako, Glostrup, Denmark), a biotinylatedsheep anti-mouse antibody (Amersham, Aylesbury, UK) and Texas Red-conjugated streptavidin (Amersham) for 30 minutes. Nuclei were labeled with 4',6-diamidino-2-phenylindole (DAPI; $1 \mu \mathrm{g} / \mathrm{ml}$ ) for 20 minutes. The coverslips were then mounted with Citifluor antifading solution (Agar, UK) onto glass slides and the slides were observed under a Zeiss fluorescence microscope.

For vimentin-actin double immunolabeling, monolayers were successively (with intermediate washes) incubated with a rabbit anti-actin antibody (Sigma) for 1 hour, then with fluorescein isothiocyanate (FITC)-conjugated swine-anti rabbit IgG (Dako) and CY3-conjugated anti-vimentin monoclonal antibody (Dako). The cell nuclei were labeled with DAPI for 20 minutes before they were mounted and observed as described above.

\section{BrdU incorporation, detection and evaluation of cell proliferation}

Cell monolayers were incubated with BrdU (5-bromo-2'-deoxyuridine: $100 \mu \mathrm{M}$ in serum-free medium) for 30 minutes before they were fixed in cold methanol for 10 minutes. Cells were then exposed to $\mathrm{HCl}(2$ $\mathrm{N})$ for 20 minutes to ensure DNA denaturation and neutralized by several washes with sodium tetraborate $(0.1 \mathrm{M}, \mathrm{pH} 8.5)$ and with PBS. For BrdU detection, monolayers were then incubated 30 minutes with an FITC-conjugated anti-BrdU antibody (Becton Diskinson, San Jose, CA). For vimentin-BrdU double immunolabeling, monolayers were successively labeled for vimentin then for BrdU. The cell nuclei were then labeled with DAPI for 20 minutes before the coverslips were mounted and observed as described above. For the evaluation of the percentage of BrdU incorporating cells in the ring system, slides were observed under a fluorescent microscope (Olympus, Melville, NY) equipped with a Sony 3CCD color video camera (DXC-9100P, Sony) and the nuclei (blue for DAPI and green for BrdU) were quantified using an Olympus microimage analysis software (version 3.0.1). 5 fields (magnification: $\times 20$ ) at the edge of the outgrowth were quantified for each cell line.

\section{In situ hybridization}

The wounded cultures were fixed for 10 minutes in $4 \%$ paraformaldehyde in PBS, dehydrated in ethanol $50 \%$ and $70 \%$, rehydrated and treated with $0.2 \mathrm{~N} \mathrm{HCl}$ for 20 minutes at room temperature. They were then washed in $2 \times \mathrm{SSC}$, acetylated in $0.25 \%$ acetic anhydride in $0.1 \mathrm{M}$ triethanolamine for 10 minutes and hybridized overnight with ${ }^{35} \mathrm{~S}$-labeled vimentin antisense RNA transcripts. These probes were prepared from the vimentin cDNA insert which had been cloned into pGEM3 (kindly provided by Dr Gelmann). The samples were then treated with RNase $(20 \mu \mathrm{g} / \mathrm{ml})$ for 1 hour at $37^{\circ} \mathrm{C}$ to remove the unhybridized probes, washed under stringent conditions and detected autoradiographically by exposure to D19 emulsion (Kodak, Rochester, NY) for 15 days. The control slides were treated under the same conditions but were hybridized with ${ }^{35} \mathrm{~S}$-labeled sense probes.

\section{Northern blotting analyses}

Total RNA were isolated from the different cell lines using RNA instapure (Eurogentec, Seraing, Belgium). Each RNA (10 $\mu \mathrm{g})$ was then analyzed by electrophoresis through $1 \%$ agarose gels containing $10 \%$ formaldehyde and transferred onto nylon membranes (Amersham). The membranes were then hybridized either with a vimentin probe generated by PCR using the vimentin CDNA as the template (from base $866-1190$ on the vimentin sequence published by Ferrari et al. (1986), GenBank accession number M14144) or with a puromycin probe. Probes were labeled with ${ }^{32} \mathrm{P}$ using a random priming labeling kit (Boehringer).

\section{Statistical analyses}

Data are expressed as means \pm standard deviation. Student's $t$-test was used to compare the migration speeds of the cells under various experimental conditions and to compare the proliferation and BrdU incorporation ability of the different transfectants. A one-way analysis of variance (ANOVA) was used to test the effect of vimentin sense or antisense transfections on both vimentin expression and cell migration speeds and of vimentin expression on cell migration speeds. A $P$ value of $<0.05$ was considered significant.

\section{RESULTS}

\section{In vitro wound healing: a model to visualize and quantify the migratory status}

To study the dynamics of vimentin expression during epithelial cell migration, we first devised an in vitro wound-healing model that allowed the regulation and quantification of human mammary MCF10A cell migration. In this assay, after a circular wound was created in a confluent monolayer, the cells were induced to migrate and progressively recolonized the damaged area. As shown in Fig. 1A and C, wound closure was achieved 96 hours after the wounding procedure in growth medium. Even though cell proliferation is likely to contribute to the wound closure, time-lapse video recording over a 1 hour period, allowed us to quantify the migration speed of individual cells and their trajectories. Indeed, cells at the wound's edge were involved in a directed migration towards the center of the injured area (Fig. 1A) and lamellipodia were clearly identified in migratory cells (Fig. 1B). The speed of cell movement was directly proportional to the distance from the wound's edge (Fig. 2A and B). Cells at the wound's edge attained speeds of $40 \mu \mathrm{m} /$ hour whereas cells located at $1.2 \mathrm{~mm}$ away were basically stationary even though they moved erratically at about $20 \mu \mathrm{m} /$ hour.

\section{Vimentin expression in MCF10A cells is transiently associated with their migratory status}

To assess the potential role of EMT in the acquisition of migratory properties by MCF10A cells, vimentin expression in the injured cultures was examined as a function of the migratory status. We found that vimentin was preferentially 
A
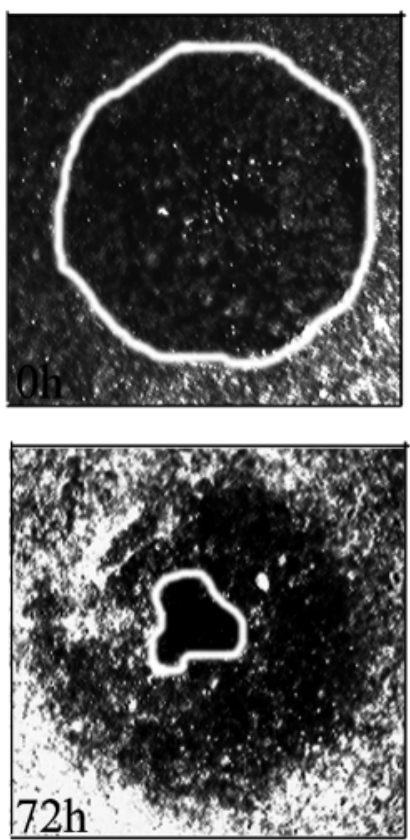
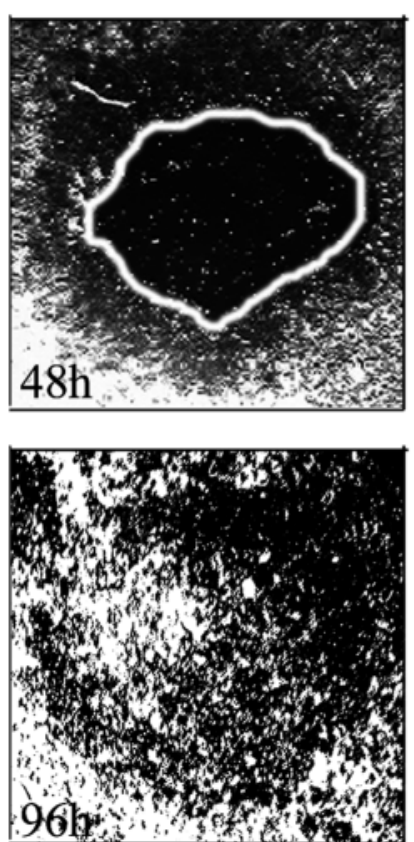

B

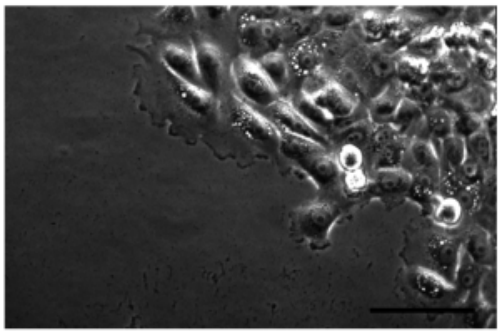

C

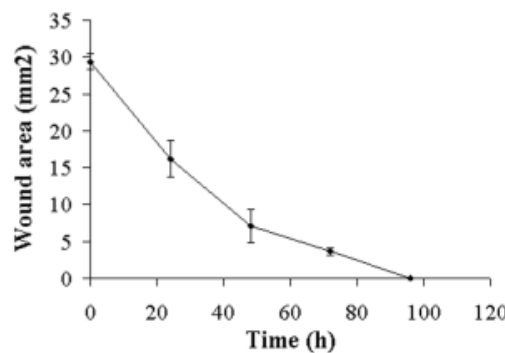

Fig. 1. In vitro wound-healing model-quantification of the wound closure. (A) Sequential video images of a wounded monolayer of MCF10A cells, taken immediately, 48, 72 or 96 hours after wounding. (B) Phase-contrast micrographs of MCF10A cells at the wound's edge. Bar, $40 \mu \mathrm{m}$. (C) Time-course measurements of the wounded area.

A
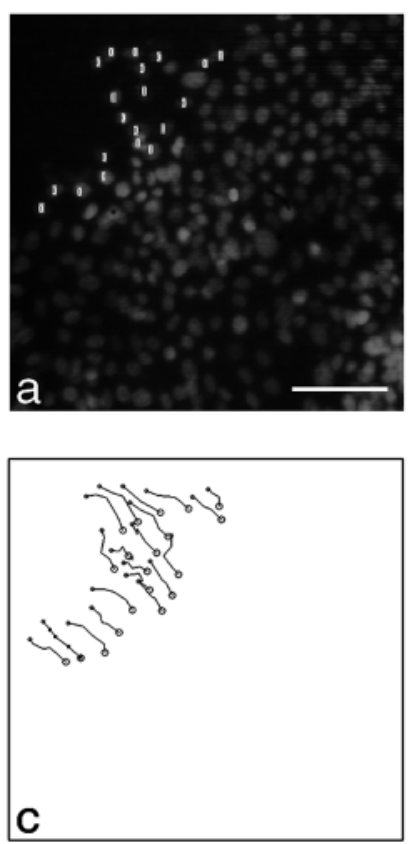
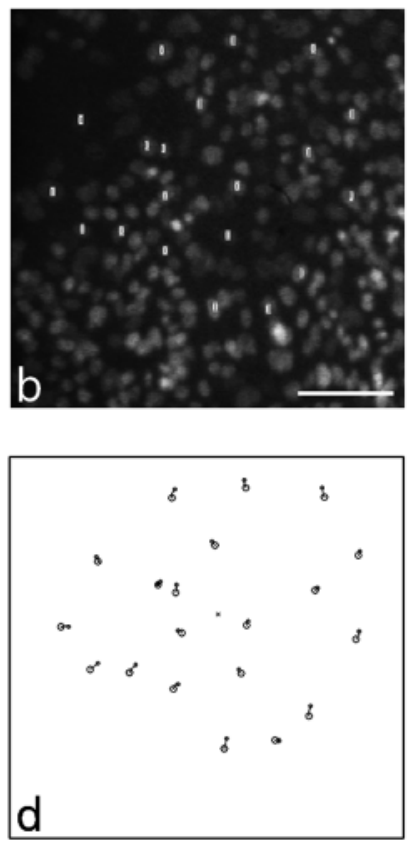

B

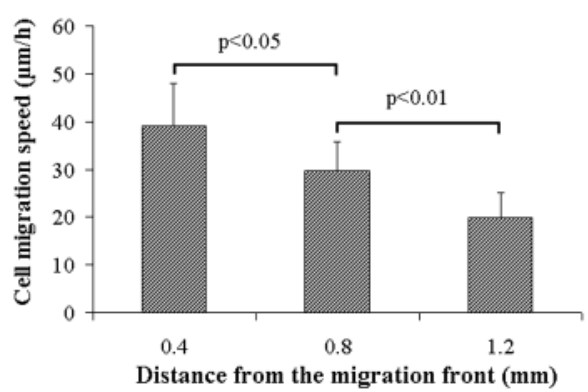

Fig. 2. Trajectories of the cell nuclei (A) and cell migration speed (B) in different areas of a wounded culture. (A) Images of nuclei stained with Hoechst dye and visualized under epifluorescence illumination (a: at the wound's edge; $b: 1.2 \mathrm{~mm}$ from the edge). Trajectories of 20 randomly selected nuclei (indicated with a white dot on a and b) were quantified in each area (c: at the wound's edge; d: at $1.2 \mathrm{~mm}$ from the migration front). Bars, $80 \mu \mathrm{m}$. (B) Speed of the cells in different areas of a wounded culture $(0.4,0.8$ and $1.2 \mathrm{~mm}$ from the wound's edge). detected in cells located at the wound's edge which were involved in active migration towards the center of the lesion (Fig. 3A). Time course experiments showed no vimentin in the cultures at the time of wound induction ( 0 hours), whereas its expression was visible in the migrating population (cells at the wound's edge) as early as 16 hours after injury. Vimentin was expressed throughout the migration process but had disappeared 96 hours after the visual wound closure was achieved (Fig. 3B), demonstrating that vimentin expression is inducible and can be reversed once a confluent monolayer is restored. To evaluate the contribution of transcriptional regulation of vimentin to this process, in situ hybridization was performed on the damaged cultures and vimentin mRNA was detected exclusively in migrating cells at the wound's 


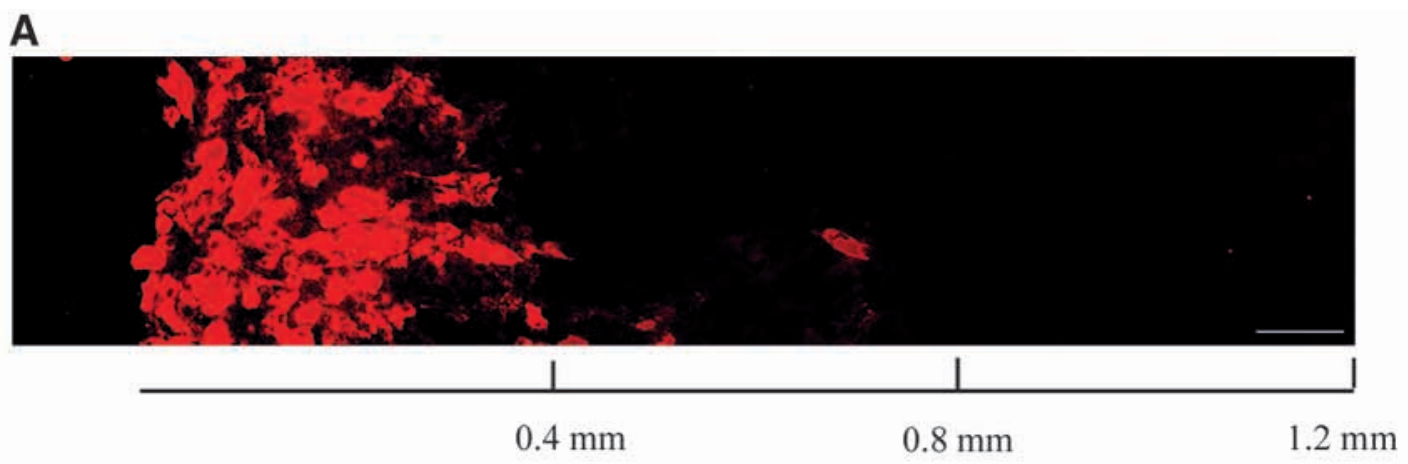

B
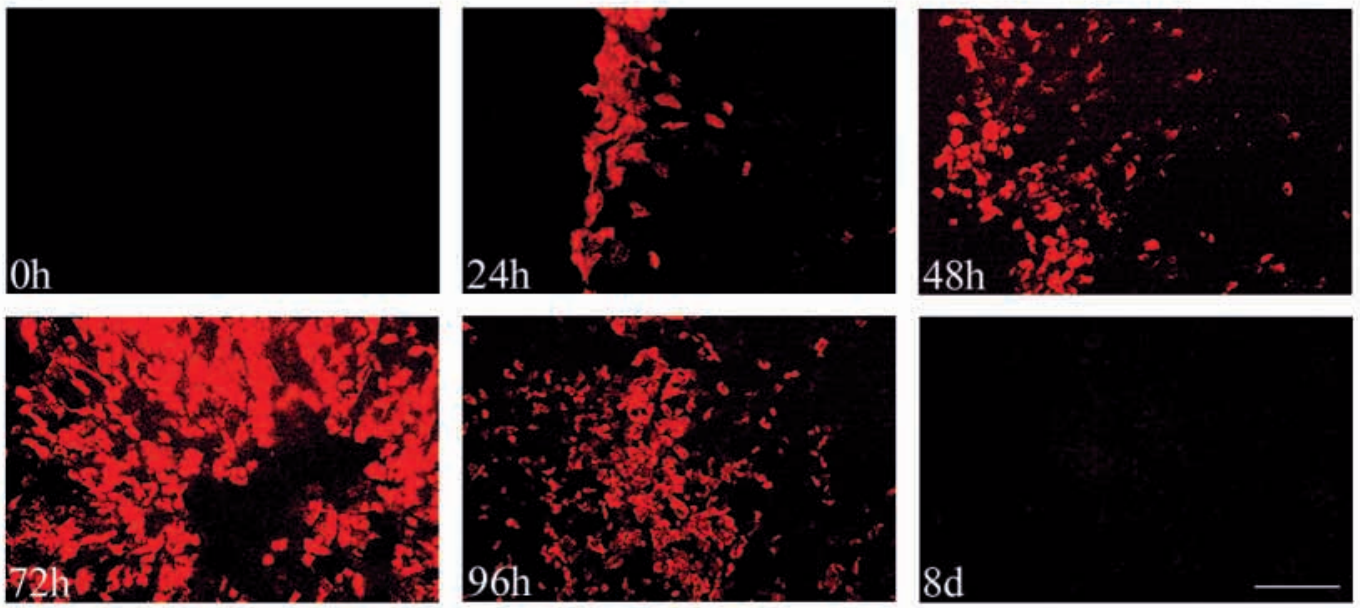

C

D

E
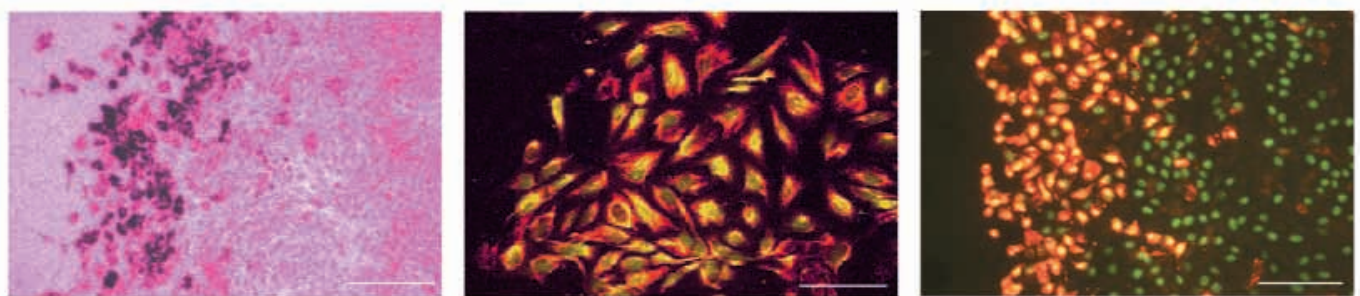

Fig. 3. Specific vimentin expression in MCF10A cells at the wound edge. (A) Vimentin immunolabeling of a wounded culture of MCF10A cells 48 hours after injury. The distance from the wound's edge is indicated in mm. Bar, $60 \mu \mathrm{m}$. (B) Vimentin immunolabeling of wounded cultures of MCF10A cells immediately (0h), 24, 48, 72, 96 hours or 8 days (8d) after injury. Bar, $80 \mu \mathrm{m}$. (C) In situ hybridization to a wounded culture of MCF10A cells performed with a vimentin antisense probe 48 hours after injury. Bar, $80 \mu \mathrm{m}$. (D) Vimentin (in red) immunolabeling of a wounded culture of VP-EGFP-transfected cells (GFP in green) 48 hours after injury. Cells expressing both proteins appear in yellow. Bar, $60 \mu \mathrm{m}$. (E) Vimentin(red)-BrdU (green) double immunolabeling of a wounded monolayer of MCF10A cells 48hours after wounding. Cells labelled for both vimentin and BrdU appear in yellow. Bar, $80 \mu \mathrm{m}$.

edge (Fig. 3C). In addition, in MCF10A clones transfected with the vector containing the vimentin promoter and the GFP gene as the reporter gene (VP-EGFP), GFP expression coincided well with the presence of vimentin in cells at the wound's edge (Fig. 3D). Nevertheless, GFP was expressed in more cells than vimentin, emphasizing the delay between promoter activation and protein synthesis. This finding demonstrates that the vimentin promoter activates transcription in migrating cells at the edge of the wound but not in more distant stationary cells.

To exclude the possibility that the vimentin expressing cells at the wound edge would represent a subpopulation of proliferating cells and that vimentin expression could therefore be associated exclusively to cell proliferation rather than to cell migration, we analysed vimentin expression in relation with the expression of the proliferation marker Mib-1 and with 
A
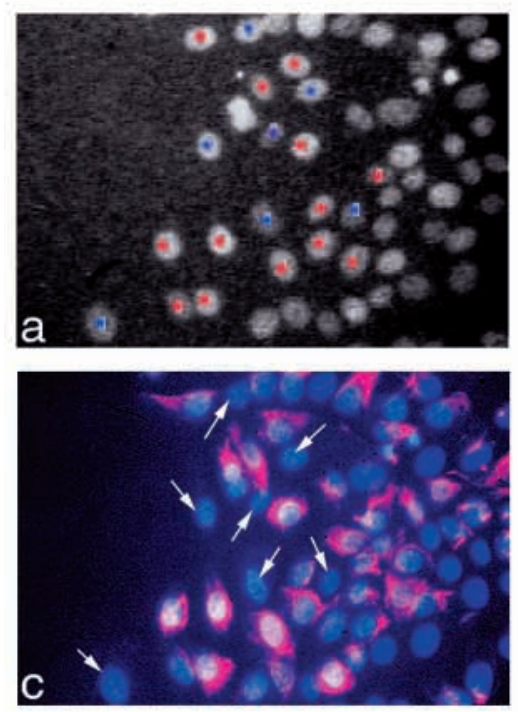
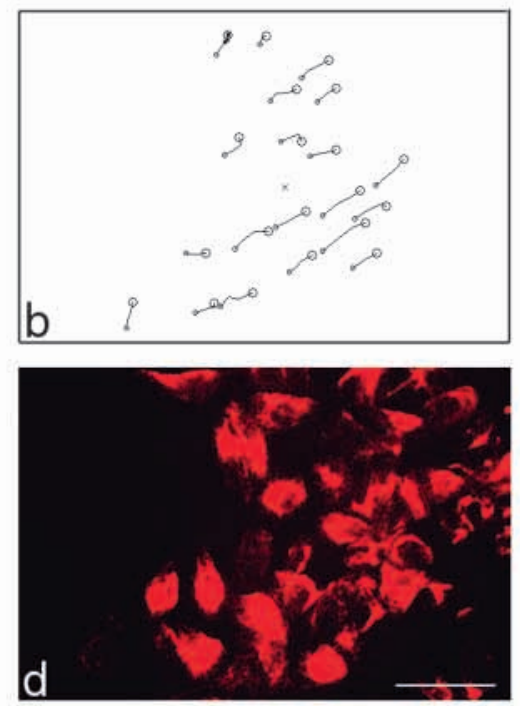

B

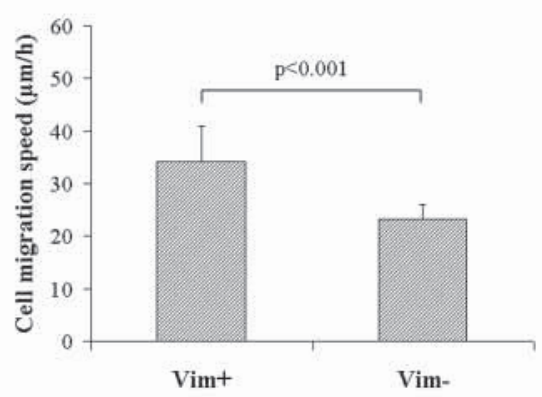

Fig. 4. Positive correlation between vimentin expression in MCF10A cells and high migration speed. (A, a) Image of Hoechst-labeled nuclei at the wound's edge of an injured MCF10A monolayer 48 hours after wounding. Twenty nuclei were selected for the trajectory analyses shown in A, b. Within these twenty cells, the vimentin-expressing cells have been labeled with a red dot whereas the vimentin negative ones with a blue dot. (A, c) Double-exposure of the same monolayer after vimentin immunolabeling and DAPI visualization of cell nuclei. Arrows point at vimentin-negative cells selected for the trajectory analyses. (A, d) Single exposure photo of the vimentin immunolabeling of the same area. Bar, $60 \mu \mathrm{m}$. (B) Histogram comparing the migration speeds, calculated from the trajectory analyses shown in (A, b), between vimentin-positive $(\mathrm{Vim}+)$ and vimentin-negative (Vim-) cells present in the wound edge area.

BrdU-incorporation. This clearly revealed that vimentin expression is not specifically associated with cell proliferation since it was restricted to the subpopulation of cells at the wound edge whereas both BrdU (Fig. 3E) or Mib-1 (data not shown) labelings were more largely distributed and not limited to the wound edge.

The association of vimentin with cell migration was further emphasized by our findings that, within cells at the wound's edge, those expressing vimentin migrated significantly more rapidly that the rare vimentin-negative cells present in this area (34.2 \pm 6.6 vs $23.2 \pm 2.8 \mu \mathrm{m} /$ hour; Fig. 4A,B).

In order to extend our observations to another human epithelial cell system, we examined vimentin expression as a function of cell migration in primary human epithelial airway cells, previously shown to migrate in the wound healing assay (Zahm et al., 1997; Legrand et al., 1999). We found the same pattern of vimentin expression in these cells than in the MCF10A cells with an induction of vimentin in migratory cells at the wound edge (data not shown). These results also validated the model of MCF10A cells as an adequate inducible model to study vimentin induction as a physiological process associated with cell migration.

\section{Actin is reorganized in migrating MCF10A cells}

Because actin reorganization has been extensively implicated in lamellipodium extension and cell migration, vimentin-actin double labeling experiments were performed on injured MCF10A cultures 48 hours after wound induction. Reorganization of actin filaments in the migrating vimentinexpressing cells was observed compared to stationary cells. The actin filaments were clearly organized as an advancing front in the lamellipodia of cells at the wound's edge whereas they circumscribed stationary cells. The vimentin filaments extended from the nuclear region to the plasma membrane of migratory cells (Fig. 5).

\section{EGF induces vimentin expression and cell migration}

Since previous studies of our group have shown that EGF enhances cell migration of human primary airway cells, we examined its influence on cell migration and vimentin expression in our MCF10A model (Zahm et al., 1993). EGF clearly induced cell migration and promoted wound closure at about the same rate as the complete growth medium (data not shown). In contrast, cells cultivated in FCS+EGF-free medium did not colonize the wounded area (data not shown). In EGFtreated cultures, vimentin was observed in cells at the wound's edge whereas no vimentin filaments were detected in absence of EGF (Fig. 6). As demonstrated with FCS-treated cultures,
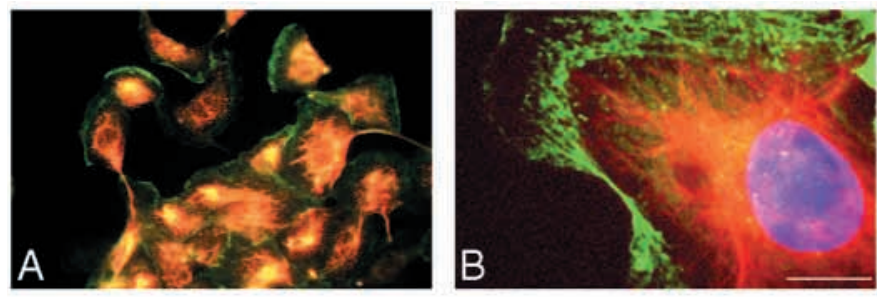

Fig. 5. Actin reorganization in migrating vimentin-expressing MCF10A cells at the edge of the wound. (A,B) vimentin (red)-actin (green) double immunolabeling of a wounded monolayer of MCF10A cells. Bars: $30 \mu \mathrm{m}$ (A); $2 \mu \mathrm{m}$ (B). Cell nuclei, labeled with DAPI, appear in blue. 
vimentin expression in EGF-treated cells was therefore also associated with cell migration. In contrast, the absence of vimentin in FCS+EGFdeprived wounded cultures, was associated with significantly lower cell migration speeds $(28.8 \pm 8.5$ vs $8.7 \pm 2.3 \mu \mathrm{m} /$ hour; Fig. $6 \mathrm{~A}, \mathrm{~B})$. Accordingly, the use of VP-EGFP-transfected clones demonstrated the activation of the vimentin promoter in cells at the wound's edge in EGF-treated but not in EGFdeprived cultures (data not shown).

\section{Functional contribution of vimentin to MCF10A cell migration: vimentin sense and antisense transfections}

To examine the possibility that vimentin could play a functional role in epithelial cell migration, sense and antisense human vimentin cDNA were transfected into MCF10A cells. Control cells were generated by transfection of the pIRES-EGFP vector. From these transfections, several clones and pooled populations were isolated and screened for appropriate vector expression by northern blotting (data not shown). Aiming at characterizing our transfectants, we performed growth curve experiments on 3 antisense-, 3 sense, 3 control transfectants and MCF10A parental cells. Even though antisense transfectants displayed a significantly higher doubling time than the sense or the control transfectants, it appeared that sense or antisense transfection did not importantly alter cell proliferation (the doubling times were 24.2 \pm 1.0 ; $20.6 \pm 1.7 ; 19.4 \pm 2.7$ and $19.4 \pm 1.7$ hours for the antisense, the sense, the control transfectants and the parental MCF10A cells, respectively). Also, BrdU incorporation experiments showed no significant differences in the percentage of cells incorporating BrdU between the same 3 sense, 3 antisense and 3 control-vector transfectants when placed in the ring system $(38.1 \pm 4.2 ; 34.3 \pm 4.5$ and $38.7 \pm 5.0 \%$ for the antisense, the sense and the control transfectants, respectively). A major effect of vimentin sense or antisense transfection on cell proliferation being excluded, we examined cell migration of our transfectants in the ring system. Even though the ring system gave similar results as the wound healingprocedure in terms of vimentin expression and nuclear trajectories it should, however, be mentioned that the migration speeds of parental MCF10A cells at the edge of the outgrowth in the ring system were higher than those observed for cells at the wound's edge in the wound-induction procedure (respectively $53.9 \pm 10.6$ vs $39.0 \pm 1.2 \mu \mathrm{m} /$ hour). Using this system, we studied in greater details the cell migration speeds of 4 pooled populations of control-vector transfectants, 3 pooled populations and 5 clones of antisense transfectants and 2 pooled populations and 2 clones of sense transfectants in 3 independent migration experiments. Variance analysis demonstrated that transfection of MCF10A cells with the vimentin antisense cDNA significantly altered $(P<0.05)$ the ability of cells to express
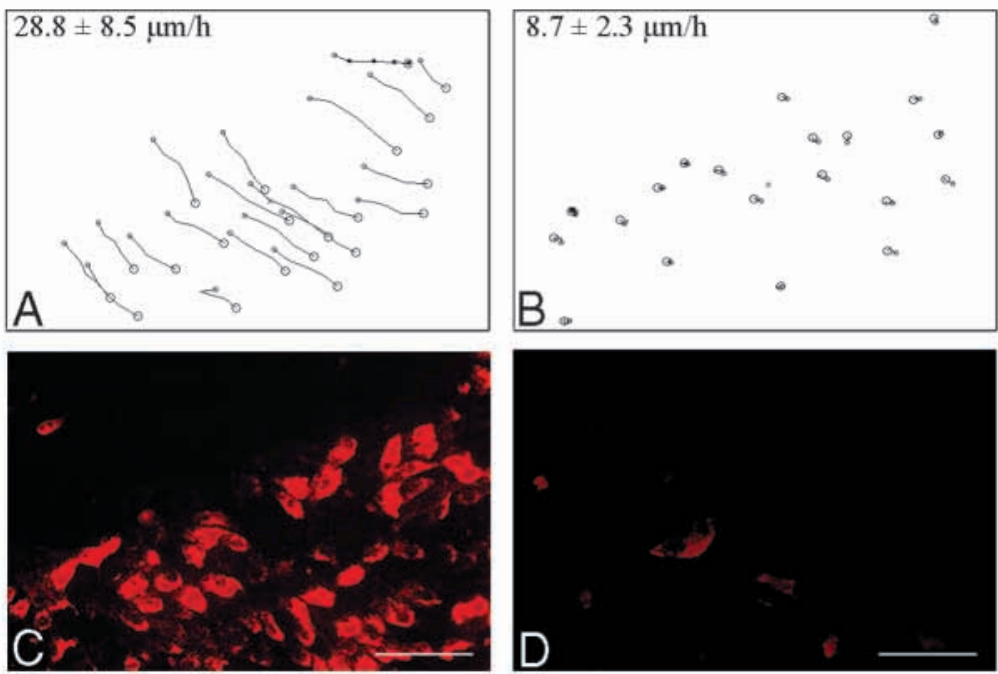

$+\mathrm{EGF}$

- EGF

Fig. 6. Effect of EGF on the rapidity of wound closure, vimentin expression and on cell migration speeds in MCF10A cells. (A,B) Trajectories of 20 cell nuclei at the wound's edge of an injured MCF10A monolayer grown in (A) FCS+EGF-free medium (Control) or in (B) FCS+EGF-free medium supplemented with EGF at $20 \mathrm{ng} / \mathrm{ml}$ (EGF), for 48 hours after wound induction. The migration speeds calculated from these trajectories are indicated. (C,D) Vimentin immunolabeling of the corresponding areas. Bars, $80 \mu \mathrm{m}$.
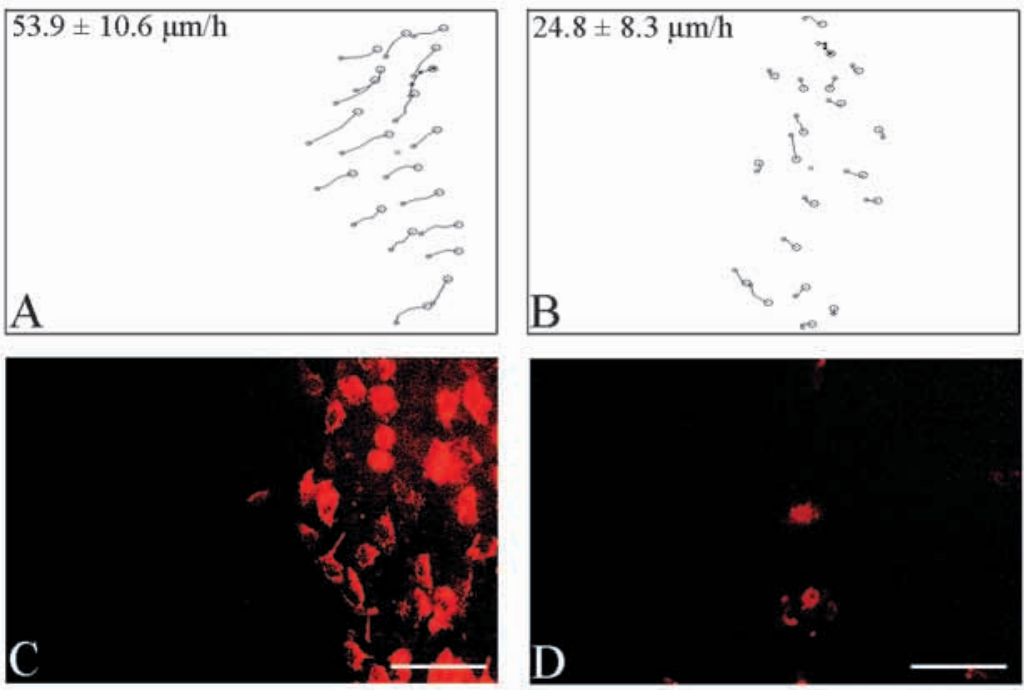

Control

VimAS

Fig. 7. Reduction of both vimentin expression and cell migration speed by vimentin antisense transfection. A representative experiment comparing a vector-control (Control) and a vimentin antisense transfectant (VimAS) is shown in the figure. $(\mathrm{A}, \mathrm{B})$ Trajectories of 20 cell nuclei at the edge of the outgowth of a control vector pIRES-EGFP-transfected population (Control) and of a vimentin antisense-transfected clone (VimAS), 72 hours after ring removal. The migration speeds calculated from these trajectories are indicated. (C,D) Vimentin immunolabeling of the corresponding areas. Bars, $80 \mu \mathrm{m}$. 
vimentin. In addition, the cell migration speed was significantly dependent on the transfection $(P<0.05)$ and on vimentin expression $(P<0.05)$. All the antisense transfectants indeed expressed less vimentin (with variation from one clone to another) at the edge of the outgrowth when compared to MCF10A clones transfected with the control vector. The antisense-mediated inhibition of vimentin expression in cells edging the outgrowth coincided with a significantly decreased migratory speeds compared to the control-vector transfectants (Fig. 7). The extend of the migration speed slowing clearly depended on the level of vimentin expression, and attained 40 to $50 \%$ in antisense transfectants whose vimentin expression was the most strongly inhibited. Although sense-vimentin cDNA-transfected clones and pooled populations constitutively expressed vimentin independently of their distance from the edge of the outgrowth, they did not migrate significantly faster than control transfectants (data not shown).

\section{DISCUSSION}

\section{Association of vimentin with epithelial cell migration}

In the present study, vimentin expression was examined in human mammary epithelial MCF10A cells as a function of their migratory status. Using an in vitro wound healing model, we clearly showed that vimentin was specifically induced in the subpopulation of MCF10A cells at the wound's edge. Vimentin protein and mRNA were induced in this cell subpopulation as assessed by immunolabeling and in situ hybridization, respectively. In support of our in situ hybridization results, the data obtained with MCF10A cells transfected with the vimentin promoter controlling the GFP reporter gene revealed a specific activation of the vimentin promoter in cells located at the wound's edge. These results are in agreement with our and other's previous results which have described vimentin expression in epithelial cells involved in wound healing (SundarRaj et al., 1992; Buisson et al., 1996) or other processes requiring cell migration (Savagner et al., 1994; Guarino, 1995; Hay, 1995; Gilles and Thompson, 1996).

Our present data obtained with a cellular model in which vimentin expression could be induced and studied in relation with cell migration nevertheless allowed to establish for the first time a direct relationship between these two functions. The time-lapse video recordings indeed demonstrated that the vimentin-expressing subpopulation of MCF10A cells at the wound's edge are actively migrating. Also, proliferation studies excluded the possibility that vimentin expression could be associated to cell proliferation rather than cell migration. In addition, the observation that, among cells at the wound's edge, those expressing vimentin migrated faster than the scarce vimentin-negative ones further strengthened the concept that vimentin is associated with the migratory status. We accordingly demonstrated that cells distant from the lesion did not express vimentin, moved erratically without an orientated trajectory and remained essentially stationary. Furthermore, MCF10A cells at the wound's edge formed lamellipodia and their actin filaments were reorganized, events typical of a migratory phenotype. Actin reorganization in migrating cells at the leading front is indeed a key-element in the extension of lamellipodia associated with cell movements (Welch et al., 1997). In MCF10A cells at the wound's edge, actin clearly formed a rim in extending lamellipodia, a feature previously described as representative of the migratory phenotype of B16 melanoma cells (Ballestrem et al., 1998). Our findings that both vimentin expression and directed active cell migration are concomitantly induced by EGF in cells at the wound edge also strengthened the theory that vimentin expression in epithelial cells is associated with the migratory status. Indeed, EGF has been shown to enhance the migratory properties of some human epithelial cell lines (Matthay et al., 1993; Solic and Davies, 1997; Charvat et al., 1998; Murakami et al., 1998) and several primary human epithelial cell types (Barrandon and Green, 1987; Stampfer and Bartley, 1988; Chen et al., 1993; Zahm et al., 1993; Wilson et al., 1994; Moulin, 1995; Andresen and Ehlers, 1998; Ellerbroek et al., 1998; McCawley et al., 1998). Even though the regulatory elements involved in the EGF-activation of the vimentin promotor have not been identified, several transcription factors, known to be activated by EGF, are likely to be implicated. The vimentin promotor indeed contains several binding sites for transcription factors such as AP-1, members of the ets family or the TCF/LEF-1 transcription factor, shown to promote the EGF-activation of invasion/migration-associated genes (Rittling et al., 1989; Lilienbaum and Paulin, 1993; Miller and Moon, 1996; Watabe et al., 1998; Tomic-Canic et al., 1999). Moreover, some transcription factors (including PEA-3, a member of the ets family) have been directly implicated in the differential regulation of the human vimentin promoter in invasive, constitutively vimentin-expressing cell lines versus noninvasive, vimentin-negative human cell lines (Sommers et al., 1994; Stover et al., 1994; Chen et al., 1996; Moura-Neto et al., 1996).

Taken together with these data, our findings suggest that the cells at the the wound's edge represent a cell subpopulation with an active migratory phenotype, and that the acquisition of this phenotype involves or leads to vimentin expression through activation of the vimentin promoter. The observation of vimentin's disappearance after wound closure, further demonstrates that its expression can be reversed and clearly suggests that vimentin can be transiently expressed in epithelial cells concomitantly with their migratory properties.

\section{Functional contribution of vimentin to epithelial cell migration}

Not only does vimentin expression coincide with the migratory status, but the protein appears to have a functional role in cell migration as emphasized by our antisense-transfection experiments. Indeed, evaluating vimentin expression and quantifying the cell-migration speeds of these transfectants in the ring system, we found that vimentin antisense transfection into MCF10A cells led to less vimentin expression in advancing outgrowth cells. This decreased vimentin induction was accompagnied by slower migration speeds of these advancing cells than those of MCF10A cells transfected with the control vector. In agreement with our findings, Hendrix et al. (1997) showed that transient transfection of vimentin antisense oligonucleotides into MDA-MB-231 breast carcinoma cells (which constitutively express vimentin) resulted in diminished in vitro invasive properties. Taken together, all these data clearly demonstrate that interfering with stable or inducible vimentin expression in epithelial cells diminish their migratory/invasive potential and therefore 
suggest a functional contribution of vimentin to cell migration. On the other hand, our sense transfection generated clones which constitutively expressed vimentin independently of their migratory status but did not significantly alter the migration speeds of cells located at the outgrowth's periphery. This observation suggests that the endogenous induction of vimentin in MCF10A cells at the wound's or outgrowth's edge is sufficient to ensure their migration and that overexpressing vimentin in these cells does not further enhance their migratory properties. Accordingly, Sommers et al. (1992) did not find any modifications of the invasiveness of MCF-7 cells transfected with the human vimentin sense cDNA. Nevertheless, Hendrix et al. (1997) reported increased invasiveness of stable vimentin-negative human MCF-7 cells transfected with the mouse vimentin sense cDNA. It remains therefore controversial whether forcing vimentin expression in stable vimentin-negative cells is sufficient to induce invasive properties. Nonetheless, even though vimentin might not be sufficient to induce migratory properties in epithelial cells, the antisense transfection experiments suggest that it could be functionally involved in, and necessary to epithelial cell migration.

In apparent contrast with these findings, vimentin knockout mice have been shown to develop without any obvious phenotype (Colucci-Guyon et al., 1994) even though alterations of the glial fibrillary acidic protein (GFAP) network have been reported in astrocytes of these mice (Galou et al., 1996). Compensatory mechanisms are also likely to occur between vimentin and other intermediate filament proteins which would participate to the normal development of these vimentin knockout mice. It has been recently shown that scar formation in response to spinal or brain lesions are normal in vimentin or in GFAP knock-out mice but not in mice deficient for both GFAP and vimentin, emphasizing a functional overlap between these two proteins (Pekny et al., 1999). It has nevertheless been suggested that phenotypic alterations of vimentin-deficient cells could be distinguished in stress (such as wound healing) or pathological (such as tumor progression) situations. In agreement with our data, Eckes et al. (1998) indeed demonstrated that fibroblasts derived from vimentin-deficient mice migrated more poorly in a wound-healing system. They also reported diminished mechanical stability and severely impaired ability of those fibroblasts to reorganize collagen fibrils and to contract collagen lattices. Changes of cell shape and mechanical stability have also been reported by Goldman et al. (1996) in 3T3 fibroblasts microinjected with peptides spanning helix-initiation domain $1 \mathrm{~A}$ of vimentin. Considering those data obtained with fibroblasts and our present results with epithelial cells, it can be deduced that vimentin might also play a functional role in epithelial cell migration associated with stress or pathological situations.

\section{Potential contribution of vimentin in epithelial cell migration}

How vimentin could functionally contribute to epithelial cell migration remains elusive. It has been shown in fibroblasts that vimentin filaments join the plasma membrane to the nucleus and might participate in the formation of focal contacts (Green and Goldman, 1986; Klymkowsky et al.,
1989). Similarly, Eckes et al. (1998) examined fibroblasts derived from vimentin-deficient mice and reported that the spatial arrangement of proteins involved in focal contacts such as vinculin, talin or paxillin was altered. Double immunofluorescence labeling of quail fibroblasts also showed that vinculin colocalized with the end of vimentin fibrils (Bershadsky et al., 1987). Similarly, Seifert et al. (1992) reported the codistribution of vimentin, vinculin, plectin (shown to bind vimentin in vitro) and focal contacts in rat glioma cells. Vimentin has also been implicated as a mechanical transducer between cell-surface integrins and endothelial cell nuclei (Maniotis et al., 1997). Furthermore, vimentin was also shown to interact with microfilaments and microtubules (Goldman et al., 1986; Seifert et al., 1992; Draberova and Draber, 1993; Svitkina et al., 1996). Indeed, it has been reported that vimentin interacted with detyrosinated microtubules in the leading edge of migrating fibroblasts in an in vitro wound healing system (Gurland and Gundersen, 1995). A concomitant redistribution of vimentin and actin filaments was also described in PDGF-treated endothelial cells (Valgeirsdottir et al., 1998). All these data suggest a role for vimentin in the mechanotransduction of signals via integrins, but also in the overall organization and integrity of the cytoskeleton which are crucial for the control of shape, motility and migration of mesenchymal cells. Our demonstration of a reorganization of actin filaments in vimentin-expressing cells at the wound's edge is in agreement with those data. However, we could not establish a direct relationship between actin reorganization and the presence of vimentin, since some vimentin-negative cells exhibited the same actin distribution as the vimentin-positive ones. Whether vimentin in epithelial cells involves mechanisms similar than those described above for fibroblasts or endothelial cells thus remains to be ascertained and is under investigation.

Taken together, our results clearly demonstrate that vimentin expression in epithelial MCF10A cells is closely related to their migratory status. Vimentin expression was indeed induced exclusively in cells at the wound's edge which are involved in directed migration towards the center of the lesion. The disappearance of vimentin after wound closure also suggests that this phenomenon is reversible and that vimentin expression is transiently associated with the migratory status. Our antisense-transfection experiments further suggest that vimentin may play a functional role in cell migration.

We thank Dr Gelmann for the generous gift of the human vimentin cDNA, Dr S. Rittling for the human vimentin promoter (pG4F1EM1.5) and Dr E. Puchelle for critical reading of the manuscript.This work was supported by grants from the 'Communauté Française de Belgique (Actions de Recherches Concertées 95/00-91)'; from the Commission of European Communities (BIO-CT960464); from the 'Fonds de la Recherche Scientifique Médicale (no./ 3.4573.95 and 3.4595.98)'; from the 'C.G.E.R. (Assurance 1996/1999)'; from the 'Fonds National de la Recherche Scientifique (F.N.R.S., Brussels, Belgium)'; from the 'Association Sportive contre le Cancer'; from the 'Centre Anticancéreux près l'Université de Liège'; the 'Fonds d'Investissements de la Recherche Scientifique (C.H.U., Liège, Belgium), from the 'Fondation Mr et Mme Braconier-Lamarche' and from the Lions Club of Soissons (France). C.G. is a Research Associate from the F.N.R.S. (Belgium). 


\section{REFERENCES}

Andresen, J. L. and Ehlers, N. (1998). Chemotaxis of human keratinocytes is increased by platelet-derived growth factor-BB, epidermal growth factor, transforming growth factor-alpha, acidic fibroblast growth factor, insulinlike growth factor-I, and transforming growth factor-beta. Curr. Eye Res. 17, 79-87.

Ballestrem, C., Wehrle-Hallerand, B. and Imhof, B. A. (1998). Actin dynamics in living mammalian cells. J. Cell Sci. 111, 1649-1658.

Barrandon, Y. and Green, H. (1987). Cell migration is essential for sustained growth of keratinocyte colonies: the roles of transforming growth factoralpha and epidermal growth factor. Cell 50, 1131-1137.

Behrens, J., Vakaet, L., Friis, R., Winterhager, E., Van Roy, F., Mareel, M. M. and Birchmeier, W. (1993). Loss of epithelial differentiation and gain of invasiveness correlates with tyrosine phosphorylation of E-cadherin/ $\beta$ catenin complex in cells transformed with a temperature-sensitive v-SRC gene. J. Cell Biol. 120, 757-766.

Bershadsky, A. D., Tint, I. S. and Svitkina, T. M. (1987). Association of intermediate filaments with vinculin-containing adhesion plaques of fibroblasts. Cell Motil. Cytoskel. 8, 274-283.

Biddle, D. and Spandau, D. F. (1996). Expression of vimentin in cultured human keratinocytes is associated with cell-extracellular matrix junctions. Arch. Dermatol. Res. 288, 621-624.

Boyer, B., Tucker, G. C., Vallés, A. M., Franke, W. W. and Thiery, J. P. (1989). Rearrangements of desmosomal and cytoskeletal proteins during the transition from epithelial to fibroblastoid organization in cultured rat bladder carcinoma cells. J. Cell Biol. 109, 1495-1509.

Buisson, A. C., Gilles, C., Polette, M., Zahm, J. M., Birembaut, P. and Tournier, J. M. (1996). Wound repair-induced expression of stromelysins is associated with the acquisition of a mesenchymal phenotype in human respiratory epithelial cells. Lab. Invest. 74, 658-669.

Charvat, S., Chignol, M. C., Souchier, C., Le Griel, C., Schmitt, D. and Serres, M. (1998). Cell migration and MMP-9 secretion are increased by epidermal growth factor in HaCaT-ras transfected cells. Exp. Dermatol. 7, 184-190.

Chen, J. D., Kim, J. P., Zhang, K., Sarret, Y., Wynn, K. C., Kramer, R. H. and Woodley, D. T. (1993). Epidermal growth factor (EGF) promotes human keratinocyte locomotion on collagen by increasing the alpha 2 integrin subunit. Exp. Cell Res. 209, 216-223.

Chen, J. H., Vercamer, C., Li, Z., Paulin, D., Vandenbunder, B. and Stehelin, D. (1996). PEA3 transactivates vimentin promotor in mammary epithelial and tumor cells. Oncogene 13, 1667-1675.

Colucci-Guyon, E., Portier, M. M., Dunia, I., Paulin, D., Pournin, S. and Babinet, C. (1994). Mice lacking vimentin develop and reproduce without any obvious phenotype. Cell 79, 679-694.

Draberova, E. and Draber, P. (1993). A microtubule-interacting protein involved in coalignment of vimentin intermediate filaments with microtubules. J. Cell Sci. 106, 1263-1273.

Eckes, B., Dogic, D., Colucci-Guyon, E., Wang, N., Maniotis, A., Ingber, D., Merckling, A., Langa, F., Aumailley, M., Delouvée, A., Koteliansky, V., Babinet, C. and Krieg, T. (1998). Impaired mechanical stability, migration and contractile capacity in vimentin-deficient fibroblasts. J. Cell Sci. 111, 1897-1907.

Ellerbroek, S. M., Hudson, L. G. and Stack, M. S. (1998). Proteinase requirements of epidermal growth factor-induced ovarian cell invasion. Int. J. Cancer. 78, 331-337.

Ferrari, S., Battini, R., Kaczmarek, L., Rittling, S., Calabretta, B., de Riel, J. K., Philiponis, V., Wei, J. F. and Baserga, R. (1986). Coding sequence and growth regulation of the vimentin gene. Mol. Cell. Biol. 6, 3614-3620.

Galou, M., Colucci-Guyon, E., Ensergueix, D., Ridet, J. L., Giminez y Ribotta, M., Privat, A., Babinet, C. and Dupouey, P. (1996). Disrupted glial fibrillary acidic protein network in astrocytes from vimentin knockout mice. J. Cell Biol. 133, 853-863.

Gilles, C., Polette, M., Peter, W., Fusenig, N. E. and Foidart, J. M. (1994a). Differentiation ability and oncogenic potential of HPV-33- and HPV33+ras-transfected keratinocytes. Int. J. Cancer 58, 847-854.

Gilles, C., Polette, M., Piette, J., Birembaut, P. and Foidart. J. M. (1994b). Epithelial-to-mesenchymal transition in HPV-33-transfected cervical keratinocytes is associated with increased invasiveness and expression of gelatinase A. Int. J. Cancer 59, 661-666.

Gilles, C. and Thompson, E. W. (1996). The epithelial to mesenchymal transition and metastatic progression in carcinoma. Breast J. 2, 83-96.

Gilles, C., Polette, M., Piette, J., Delvigne, A. C., Thompson, E. W., Foidart, J. M. and P. Birembaut. (1996). Vimentin expression in cervical carcinomas: association with the invasive and the migratory phenotype of tumor cells. J. Pathol. 180, 175-180.

Goldman, R. D., Goldman, A. E., Green, K. J., Jones, J. C., Jones, S. M. and H. Y. Yang. (1986). Intermediate filament networks: organization and possible functions of a diverse group of cytoskeletal elements. J. Cell Sci. Suppl. 5, 69-97.

Goldman, R. B., Khuon, S., Chou, Y. H. Opal, P. and Steinert, P. M. (1996) The function of intermediate filaments in cell shape and cytoskeletal integrity. J. Cell Biol. 134, 971-983.

Green, K. J. and Goldman, R. D. (1986). Evidence for an interaction between the cell surface and intermediate filaments in cultured fibroblasts. Cell. Motil. Cytoskel. 6, 389-405.

Guarino, M. (1995). Epithelial-to-mesenchymal change of differentiation From embryogenetic mechanisms to pathological patterns. Histol. Pathol. 10, 171-184.

Gurland, G. and Gundersen, G. G. (1995). Stable, detyrosinated microtubules function to localize vimentin intermediate filaments in fibroblasts. J. Cell Biol. 131, 1275-1290.

Hay, E. D. (1995). An overview of epithelio-mesenchymal transformation. Acta Anat. 154, 8-20.

Hendrix, M. J., Seftor, E. A., Chu, Y. W., Trevor, K. T. and Seftor, R. E. (1996). Role of intermediate filaments in migration, invasion and metastasis. Cancer Metast. Rev. 15, 507-525.

Hendrix, M. J. C., Seftor, E. A., Seftor, R. E. B. and Trevor, K. T. (1997). Experimental co-expression of vimentin and keratin intermediate filaments in human breast cancer cells results in phenotypic interconversion and increased invasive behavior. Am. J. Pathol. 150, 483-495.

Klymkowsky, M. W., Bachant, J. B. and Domingo, A. (1989). Functions of intermediate filaments. Cell Motil. Cytoskel. 14, 309-331.

Legrand, C., Gilles, C., Zahm, J. M., Polette, M., Buisson, A. C., Kaplan, H., Birembaut, P. and Tournier, J. M. (1999). Airway epithelial cell migration dynamics: MMP-9 role in cell-extracellular matrix remodeling. $J$. Cell Biol. 146, 517-529.

Lilienbaum, A. and Paulin, D. (1993). Activation of the human vimentin gene by the Tax human T-cell leukemia virus. I. Mechanisms of regulation by the NF-kappa B transcription factor. J. Biol. Chem. 268, 2180-2188.

Lochter, A., Galosy, S., Muschler, J., Freedman, N., Werb, Z. and Bissel, M. J. (1997). Matrix metalloproteinase stromelysin-1 triggers a cascade of molecular alterations that leads to stable epithelial-to-mesenchymal conversion and a premalignant phenotype in mammary epithelial cells. $J$. Cell Biol. 139, 1861-1872.

Maniotis, A. J., Chen, C. S. and Ingber, D. E. (1997). Control of cell and nuclear shape by mechanical stresses transmitted from integrins to the nucleus over direct cytoskeletal interconnections. Proc. Nat. Acad. Sci. USA 94, 849-854.

Martel, C., Harper, F., Cereghini, S., Noë, V., Mareel, M. and Crémisi, C. (1997). Inactivation of retinoblastoma family protein by SV40 T antigen results in creation of a hepatocyte growth factor/scatter factor autocrine loop associated with an epithelial-fibroblastoid conversion and invasiveness. Cell Growth Differ. 8, 165-178.

Matthay, M., Thiery, J. P., Lafont, F., Stampfer, M. F. and Boyer, B. (1993). Transient effect of epidermal growth factor on the motility of an immortalized mammary epithelial cell line. J. Cell Sci. 106, 869-878.

McCawley, L. J., O'Brien, P. and Hudson, L. G. (1998). Epidermal growth factor (EGF)- and scatter factor/hepatocyte growth factor (SF/HGF)mediated keratinocyte migration is coincident with induction of matrix metalloproteinase (MMP)-9. J. Cell. Physiol. 176, 255-265.

Miller, J. R. and Moon, R. T. (1996). Signal transduction through $\beta$-catenin and specification of cell fate during embryogenesis. Genes Dev. 10, 2527 2539.

Moulin, V. (1995). Growth factors in skin wound healing. Eur. J. Cell Biol. 68, $1-7$.

Moura-Neto, V., Kryszke, M. H., Li, Z., Vicart, P., Lilienbaum, A. and Paulin, D. (1996). A 28-bp negative element with multiple factor-binding activity controls expression of the vimentin-encoding gene. Gene 168, 261266.

Murakami, N., Fukuchi, S., Takeuch, K., Hori, T., Shibamoto, S. and Ito, F. (1998). Antagonistic regulation of cell migration by epidermal growth factor and glucocorticoid in human gastric carcinoma cells. J. Cell. Physiol. 176, 127-137.

Nawrocki, B., Polette, M., Maquoi, E. and Birembaut, P. (1997). Expression of matrix metalloproteinases and their inhibitors during human placental development. Trophoblast Res. 10, 97-113.

Pekny, M., Johansson, C. B., Eliasson, C., Stakeberg, J., Wallén, A., 
Perlmann, T., Lendahl, U., Betsholtz, C., Berthold, C. H. and Frisén, J. (1999). Abnormal reaction to central nervous system injury in mice lacking fibrillary acidic protein and vimentin. J. Cell Biol. 145, 503-514.

Polette, M., Gilles, C., de Bentzmann, S., Gruenert, D., Tournier, J. M. and Birembaut, P. (1998). Association of fibroblastoid features with the invasive phenotype in human bronchial cancer cell lines. Clin. Exp. Metast. 16, 105-112.

Ramaekers, F. C., Haag, D., Kant, A., Moesker, O., Jap, P. H. and Vooijs, G. P. (1983). Coexpression of keratin- and vimentin-intermediate filaments in human metastatic carcinoma cells. Proc. Nat. Acad. Sci. USA 80, 26182622

Rittling, S. R. and Baserga, R. (1987). Functional analysis and growth factor regulation of the human vimentin promotor. Mol. Cell. Biol. 7, 3908-3915.

Rittling, S. R., Coutinho, L., Amram, T. and Kolbe, M. (1989). AP-1/jun binding sites mediate serum inducibility of the human vimentin promotor. Nucl. Acids Res. 17, 1619-1633.

Savagner, P., Boyer, B., Vallés, A. M., Jouanneau, J. and Thiery, J. P. (1994). Modulations of the epithelial phenotype during embryogenesis and cancer progression. In Mammary Tumorigenesis and Malignant Progression (ed. R. Dickson and M. Lippman), pp. 229-249. Dordrecht, The Netherlands: Kluwer Academic Publishers.

Seifert, G. J., Lawson, D. and Wiche, G. (1992). Immunolocalization of the intermediate filament-associated protein plectin at focal contacts and actin stress fibers. Eur. J. Cell Biol. 59, 138-147.

Solic, N. and Davies, D. E. (1997). Differential effects of EGF and amphiregulin on adhesion molecule expression and migration of colon carcinoma cells. Exp. Cell Res. 234, 465-476.

Sommers, C. L., Walker-Jones, D., Heckford, S. E., Worland, P., Valverius, E., Clark, R., Stampfer, M. and Gelmann, E. P. (1989). Vimentin rather than keratin expression in some hormone-independent breast cell lines and in oncogene-transformed mammary epithelial cells. Cancer Res. 49, 4258-4263.

Sommers, C., Heckford, S. E., Skerker, J. M., Worland, P., Torri, J. A., Thompson, E. W., Byers, S. and Gelmann, E. P. (1992). Loss of epithelial markers and acquisition of vimentin expression in adriamycin- and vinblastine-resistant human breast cancer cell lines. Cancer Res. 52, 51905197

Sommers, C. L., Skerker, J. M., Chrysogelos, S. A., Bosseler, M. and Gelmann, E. P. (1994). Regulation of vimentin gene transcription in human breast cancer cell lines. Cell Growth Differ. 5, 839-846.

Stampfer, M. R. and Bartley, J. C. (1988). Human mammary epithelial cells in culture: differentiation and transformation. Cancer Treat. Res. 40, 1-24.

Steinert, P. M. and Roop, D. R. (1988). Molecular and cellular biology of intermediate filaments. Аnnu. Rev. Biochem. 57, 593-625.

Stover, D. M., Carey, I., Garzon, R. J. and Zehner, Z. E. (1994). A negative regulatory factor is missing in a human metastatic breast cancer cell line. Cancer Res. 54, 3092-3095.

SundarRaj, N., Rizzo, J. D., Anderson, S. C. and Gesiotto, J. P. (1992) Expression of vimentin by rabbit corneal keratinocytes during wound repair. Cell Tissue Res. 267, 347-356.

Svitkina, T. M., Verkhovsky, A. B. and Borisy, G. G. (1996). Plectin sidearms mediate interaction of intermediate filaments with microtubules and other components of the cytoskeleton. J. Cell Biol. 135, 991-1007.

Tomic-Canic, M., Komine, M., Freedberg, I. M. and Blumenberg, M. (1999). Epidermal signal transduction and transcription factor activation in activated keratinocytes. J. Dermatol. Sci. 17, 167-181.

Tucker, G. C., Boyer, B., Gavrilovic, J., Emmonard, H. and Thiery, J. P. (1990). Collagen-mediated dispersion of NBT-II rat bladder carcinoma cells. Cancer Res. 50, 129-137.

Valgeirsdottir, S., Claesson-Welsh, L., Bongcam-Rudlof, E., Hellman, U., Westermark, B. and Heldin, C. H. (1998). PDGF induces reorganization of vimentin filaments. J. Cell Sci. 111, 1973-1980.

Vallés, A. M., Boyer, B., Badet, J., Tucker, G. C., Barritault, D. and Thiery, J. P. (1990). Acidic fibroblast growth factor is a modulator of epithelial plasticity in a rat bladder carcinoma cell line. Proc. Nat. Acad. Sci. USA 87, 1124-1128.

Watabe, T., Yoshida, K., Shindoh, M., Kaya, M., Fujikawa, K., Sato, H., Seiki, M., Ishii, S. and Fujinaga, K. (1998). The Ets-1 and Ets-2 transcription factors activate the promoters of invasion-associated urokinase and collagenase genes in response to epidermal growth factor. Int. J. Cancer 77, 128-137.

Weidner, K. M., Behrens, J., Vandekerckhove, J. and Birchmeier, W. (1990). Scatter factor: molecular characteristics and effect on invasiveness of epithelial cells. J. Cell Biol. 111, 2097-2108.

Welch, M. D., Mallavarapu, A., Rosenblatt, J. and Mitchison, T. J. (1997) Actin dynamics in vivo. Curr. Opin. Cell Biol. 9, 54-61.

Wilson, S. E., He, Y. G., Weng, J., Zieske, J. D., Jester, J. V. and Schultz, G. S. (1994). Effect of epidermal growth factor, hepatocyte growth factor, and keratinocyte growth factor, on proliferation, motility and differentiation of human corneal epithelial cells. Exp. Eye Res. 59, 665-678.

Zahm, J. M., Pierrot, D. and Puchelle, E. (1993). Epidermal growth factor promotes wound repair of human respiratory epithelium. Wound Repair Regen. 1, 175-180.

Zahm, J. M., Kaplan, H., Herard, A. L., Doriot, F., Pierrot, D., Somelette, P. and Puchelle, E. (1997). Cell migration and proliferation during the in vitro wound repair of the respiratory epithelium. Cell. Motil. Cytoskel. 37, 33-43.

Zuk, A., Matlin, K. S. and Hay, E. D. (1989). Type I collagen gel induces Mardin-Darby canine kidney cells to become fusiform in shape and lose apical-basal polarity. J. Cell Biol. 108, 903-919. 